\title{
TECHNICAL CHANGE DIRECTIONS OF CHINA'S GRAIN PRODUCTION: APPLICATION OF THE BIAS-CORRECTED MALMQUIST INDICES
}

\author{
Tianxiang $\mathrm{LI}^{1}$, Tomas BALEŽENTIS ${ }^{2}$, Lijuan $\mathrm{CAO}^{1,3}$, \\ Jing ZHU ${ }^{1,3^{*}}$, Dalia ŠTREIMIKIENE ${ }^{2}$, Rasa MELNIKIENÉ ${ }^{2}$ \\ ${ }^{1}$ College of Economics and Management, Nanjing Agricultural University, Nanjing, P.R. China \\ ${ }^{2}$ Lithuanian Institute of Agrarian Economics, Vilnius, Lithuania \\ ${ }^{3}$ China Center for Food Security, Nanjing Agricultural University, Nanjing, P.R. China
}

Received 11 January 2017; accepted 03 July 2017

\begin{abstract}
This paper aims at measuring productivity and efficiency of China's three most important grain crops-rice, wheat and maize-as well as identifying the main directions of technical change prevailing in their production. The bias-corrected Malmquist production indices are employed to measure the technical changes (TCs) in terms of input-saving or input-using in China's grain production, by using provincial aggregate data obtained from the National Farm Production Costs and Returns Survey. The research covers the period of 2004-2012. Application of the bias-corrected Malmquist index showed a labor-saving technical change against all the remaining inputs for the three crops under analysis. The highest frequencies of fertilizer- and machinery-using, labor-saving technical changes were observed for wheat farming. Therefore, a reduction in labor intensity should be the most promising for wheat if compared with rice and maize.
\end{abstract}

Keywords: grain production, technical change, technical bias, bias-corrected Malmquist index, China.

JEL Classification: C43, C44, Q10.

\section{Introduction}

China has maintained a consecutive growth in grain output for the past decade, with an annual growth rate of over $3 \%$, leading to a historical level of total output of 621.4 million tons in 2015. However, in spite of the steep increase in food production, the country's demand for food grows at a much faster pace. The deficit between food production and consumption in China persists, and is forecast to increase in the future (cf. FAO-OECD 2013; Anderson, Strutt 2012, 2014, among others). Therefore, food security is still a top priority issue for the Chinese government. In order to ensure food security, either increasing agricultural output

${ }^{\star}$ Corresponding author. E-mail: crystalzhu@njau.edu.cn

This is an Open Access article distributed under the terms of the Creative Commons Attribution License (http://creativecommons. org/licenses/by/4.0/), which permits unrestricted use, distribution, and reproduction in any medium, provided the original author and source are credited. 
domestically or increasing the volume of imports are the two possible alternatives for the country.

On the production side, as economic theories suggest, there are two major sources of growth in grain output, namely growth in factor inputs (extensive growth) and improvement in productivity (intensive growth); see Chen et al. (2008), and Xin and Qin (2011). As regards the former source, utilizing more factor inputs (i.e., land, labor, fertilizer, machinery etc.) depends on factor endowments and relative factor prices. However, in the Chinese context, factor markets have been challenged by the following issues: 1) a continuous diminution and scarcity of arable land resources because of rapid industrialization and urbanization implying a rather limited expansion of areas sown under grain crops in the future; 2) a steady increase in rural wages due to the shrinkage in surplus labor, fueled by a large-scale rural to urban labor migration and rural population aging. Together with the wage increase in China's urban economy, rural wages have been growing at about $10 \%$ annually since 2003 , thus outpacing costs related to other agricultural inputs and becoming the main driver of changes in Chinese agricultural production cost structure.

Nevertheless, severe constraints in arable land and labor force did not preclude China's grain production from achieving a relatively high growth rate in the past decade. These developments can be attributed to technological progress (i.e., the use of machinery, fertilizer, and agricultural chemicals etc.) and productivity growth (Chen 2013; Wang, Xiao 2013; Wang et al. 2013). Moreover, it is reasonable to assume that improvements in technical efficiency and productivity will remain the main drivers for further grain output growth in China. Analyzing these phenomena, therefore, is surely of great relevance in terms of practical value and policy implications.

In general, productivity and efficiency in China's agricultural production have attracted considerable attention, yet majority of previous attempts are based on data aggregated over sectors (including agriculture, forestry, animal husbandry and fishery) or crops (Fan 1991, 1997; Mao, Koo 1997; Fan, Zhang 2002; Cater et al. 2003; Hu, McAleer 2005; Chen et al. 2008; Chen and Song 2008; Monchuk et al. 2010; Wang, Rungsuriyawiboon 2010). In particular, only a handful of previous studies were focused on the grain sector (Yao, Liu 1998; Yao et al. 2001; Chen et al. 2003), with even less being focused on separate grain crops (Tian, Wan 2000).

Noteworthy, there is also a lack of studies on directions of the technical change (TC), i.e., input-saving or input-use, in China's grain production, whereas considerable amount of studies on the role of agricultural TC and productivity growth are available. Indeed, TC is viewed as a dynamic response to changes resource endowments and economic environment, and TC can bias towards certain factor of production due to the induction of a range of social and economic factors, such as relative factor prices or market demand. This was first investigated in agriculture by Hayami and Ruttan (1970), who proposed the so-called "induced innovations hypothesis", demonstrating that changes in factor endowments and price ratio among factors were associated with changes in the use of a specific type of agricultural technologies or inputs, and agricultural TCs tended to bias toward saving the limiting factor (Hayami, Ruttan 1970, 1971; Binswanger 1974).

This paper, therefore, aims at measuring productivity and efficiency of China's three most important grain crops-rice, wheat and maize-as well as identifying the main directions of 
TCs prevailing in their production. To fulfill the objectives, the bias-corrected Malmquist production indices introduced by Färe et al. (1997) will be employed in the paper. Unlike other parametric and non-parametric measures of efficiency and productivity, the bias-corrected Malmquist index relaxes the assumption of Hick's neutral technical change in productivity and efficiency analysis, by decomposing TC into the components of magnitude, output bias, an input bias (Färe et al. 1997; Nin et al. 2003; Baležentis 2014), thus enabling one to assess the biased TCs in terms of input (output) saving or deepening.

The rest of the paper is set out as follows. Section 1 presents a literature survey on efficiency and productivity of Chinese agriculture. Section 2 describes the nonparametric methodology for estimation of technical bias. Section 3 introduces the data used. Results are presented in Section 4 and further discussed in the following section.

\section{Literature review}

Since productivity growth has been widely believed to be crucial for Chinese agriculture (Yao et al. 2001; Hu, McAleer 2005; Monchuk et al. 2010; Li, Zhang 2013), agricultural productivity and efficiency in China have generally attracted considerable attention. A number of previous studies analyzed total factor productivity (TFP) growth ${ }^{1}$ in China's agricultural sector on the basis of national aggregate data by using either parametric or nonparametric methods. For example, Fan (1991), Fan (1997), Fan and Zhang (2002) applied the Stochastic Frontier Approach (SFA) and Tornqvist-Theil index to measure growth in output, input, and TFP in Chinese agriculture both before and after its rural economic reforms, while Luh et al. (2008) and Nin-Pratt et al. (2010) compared China's agricultural productivity growth and efficiency change against those in other countries using the Data Envelopment Analysis (DEA) and Malmquist indices.

Besides the national-level data, provincial statistics of China have also been extensively used to investigate regional disparity of productivity growth and patterns of technical efficiency in Chinese agriculture. These researches include the early works, see, e.g., Mao and Koo (1997), Lambert and Parker (1998) and Wu et al. (2001), which measured China's regional agricultural productivity change and its components in terms of technical change and efficiency change mainly based on the nonparametric DEA approach and Malmquist Index, and the recent studies, see, e.g., Wang and Rungsuriyawiboon (2010), Ito (2010), Zhang and Brümmer (2011), Ma and Feng (2013), Zhou and Zhang (2013), which identified the sources of China's agricultural productivity change mostly by using the parametric methodology (viz., SFA) assuming Cobb-Douglas, separated Cobb-Douglas or translog production function, and meta-frontier approach. Nonetheless, despite the differences in research methodologies and periods covered in the aforementioned literature, the conclusions drawn in these papers are almost consistent, indicating that: (1) China has experienced an impressive improvement in agricultural TFP, which was mainly driven by technical progress (namely the

\footnotetext{
${ }^{1}$ Färe et al. (2008) and O'Donnell (2012) noted that Malmquist index can serve as a TFP index only in special cases. However, much of the literature on the TFP change actually employs Malmquist productivity index. In this paper, we use term "TFP change" when referring to earlier literature and our research, yet the aforementioned caveats should be taken into account.
} 
outward movement of the production frontier), while efficiency change (namely the proximity to the production frontier) has acted against the improvement in TFP in most of the periods; (2) there have been significant regional disparities in productivity performance due to the differences in both technological innovations and efficiency enhancements.

However, as pointed out by Cater et al. (2003), because of the possible aggregation bias pertinent to the national and provincial level data sets, aggregate data may blur the true picture with regard to productivity growth in China's agricultural sector. Hence, to remedy the shortcomings mentioned above, province-level data should be applied carefully. This, therefore, motivated some studies to utilize county-level and farm household-level data to explore Chinese agricultural productivity and efficiency change, see e.g. Brümmer et al. (2006), Chen et al. (2009), Monchuk et al. (2010), Liu (2011). Though the unit of observation in these studies featured a lower aggregation level than most of the previous studies, their analysis nevertheless relied on aggregate data in terms of agricultural commodities (including crops, livestock and other individual products), i.e., few commodity-specific investigations were carried out.

Indeed, several of the earlier studies focused on the analysis of commodity-specific productivity in China. For instance, Jin et al. (2010) and Li et al. (2011) investigated the productivity of 21 agricultural commodities and 14 crops separately during the periods of 19852004 and 1978-2005. However, only a few studies explicitly devoted to the grain sector seem to have appeared in the literature. The studies of Yao and Liu (1998), Yao et al. (2001) used aggregate provincial-level data in 1987-1992 to discuss spatial differences of grain production efficiency; whereas other researches, such as Huang and Rozelle (1996) used farm householdlevel data but only focus on a certain grain crop (i.e. rice or wheat). To our knowledge, only a few papers including Tian and Wan (2000), Jin et al. (2002) shed light on the productivity of China's three or four major grain products together by using farm-level data sets, but their studies covered the period prior to 2000, and both studies employed the SFA method.

Our paper aims at measuring efficiency, productivity, and technical change patterns of grain crops in China in 2004-2012 by the virtue of the bias-corrected Malmquist index. Considering the outcomes of literature review, one can note that the present study on Chinese agricultural productivity growth differs from previous ones in terms of the following features. First, unlike most of the previous studies using aggregate national and provincial data, we will use national and provincial averages based on the data obtained from the National Farm Production Costs and Returns Survey (NFPCRS), published by the National Development and Reform Commission (NDRC). Second, given the fact that China has reached a consecutive grain output growth in the past decade, but few previous studies went beyond 2000, our study will specifically focus on productivity and efficiency change of major grain crops during 2004-2012, which should be more relevant in regards to implications for the future. Last but most importantly, while there are lots of emphasis on the role of agricultural technical change (TC) and productivity growth in China, very little attention has been paid to the TC directions in its grain production ${ }^{2}$. In a large part, this inadequacy has ultimately been due to lack of both data and methodologies. The non-parametric measures of efficiency

\footnotetext{
${ }^{2}$ For instance, Wu et al. (2001), did not discuss the types of the underlying technical bias even though bias-corrected Malmquist index was employed.
} 
and productivity do not enable to fathom the underlying technology changes in terms of input saving and consumption. However, the bias-corrected Malmquist productivity index offers a remedy to this shortcoming by relaxing the assumption of Hick's neutral technical change in productivity and efficiency analysis, and decomposing TC into the components of magnitude, output bias, an input bias (Färe et al. 1997; Nin et al. 2003; Baležentis 2014), thus enabling one to assess the biased TCs in terms of input (output) saving or deepening.

\section{Preliminaries}

\subsection{Productive technology and distance function}

A nonparametric estimation of technical bias relies on the Malmquist index (Caves et al. 1982; Färe et al. 1995a, 1995b, 1997) and Data Envelopment Analysis (Charnes et al. 1978). Assume that technology during period $t$ is defined in terms of input vectors, $x^{t} \in \mathfrak{R}_{+}^{m}$, and output vectors, $y^{t} \in \mathfrak{R}_{+}^{n}$, so that the technology set is:

$$
T^{t}=\left\{\left(x^{t}, y^{t}\right): x^{t} \text { can produce } y^{t}\right\} \text {. }
$$

The underlying technology can also be represented by an input requirement set (bounded by an isoquant):

$$
I^{t}\left(y^{t}\right)=\left\{x^{t}:\left(x^{t}, y^{t}\right) \in T^{t}\right\}
$$

which contains all the feasible input quantities for a given level of output and is bounded from below. In order to estimate technical efficiency (TE) of a certain observation, we consider the radial movement along the ray through the origin and the observation towards the lower boundary of the input requirement set. Therefore, the input distance function (Shephard 1970) can be used as a respective measure of efficiency:

$$
D^{t}\left(x^{t}, y^{t}\right)=\max \left\{\theta:\left(\frac{x^{t}}{\theta}, y^{t}\right) \in I^{t}\left(y^{t}\right)\right\},
$$

with $\theta \in[1,+\infty)$ being the maximal factor of input contraction and $\theta=1$ for efficient observations. Note that the distance function defined in Eq. (3) is contemporaneous one. Let there be $T$ time periods denoted by index $t=1,2, \ldots, T$. An inter-temporal input distance function relative to the frontier of period $s=1,2, \ldots, T$ is given by:

$$
D^{s}\left(x^{t}, y^{t}\right)=\max \left\{\theta:\left(\frac{x^{t}}{\theta}, y^{t}\right) \in I^{s}\left(y^{s}\right)\right\},
$$

Thus, Eqs. (1)-(3) enable one to define a production possibility set along its boundary and measure the distances between observations and production frontier. A cross-period analysis can be facilitated by the virtue of Eq. (4).

\subsection{Nonparametric estimator}

An empirical estimation of the underlying technology is based on a piece-wise linear approximation under assumptions of constant returns to scale (CRS), strong disposability, and convexity (cf. Shephard 1970; Färe et al. 1994a). Furthermore, there are $k=1,2, \ldots, K$ deci- 
sion making units (DMUs). Therefore, the corresponding estimator of $T^{t}$ is:

$$
T^{t}=\left\{\begin{aligned}
& \sum_{k=1}^{K} \lambda_{k} x_{i k}^{t} \leq x_{i}^{t}, i=1,2, \ldots m, \\
\left(x^{t}, y^{t}\right): & \sum_{k=1}^{K} \lambda_{k} y_{j k}^{t} \geq y_{j}^{t}, j=1,2, \ldots, n, \\
& \lambda_{k} \geq 0, k=1,2, \ldots, K
\end{aligned}\right\},
$$

where $\lambda_{k}$ are intensity variables. This setting implies that certain DMU can produce less outputs with more inputs than it were the case for any convex combination of the observed production plans under CRS.

A Data Envelopment Analysis (DEA) model then estimated the distance between a certain observation and production frontier:

$$
\begin{gathered}
\left(D^{t}\left(x^{t}, y^{t}\right)\right)^{-1}=\min _{\lambda_{k}, \phi} \\
\sum_{k=1}^{K} \lambda_{k} x_{i k}^{t} \leq \phi x_{i}^{t}, i=1,2, \ldots m, \\
\sum_{k=1}^{K} \lambda_{k} y_{j k}^{t} \geq y_{j}^{t}, j=1,2, \ldots, n, \\
\lambda_{k} \geq 0, k=1,2, \ldots, K .
\end{gathered}
$$

Similarly, an inter-temporal measure relative to reference period $s$ can be defined as:

$$
\begin{gathered}
\left(D^{s}\left(x^{t}, y^{t}\right)\right)^{-1}=\min _{\lambda_{k}, \phi} \phi \\
\sum_{k=1}^{K} \lambda_{k} x_{i k}^{s} \leq \phi x_{i}^{t}, i=1,2, \ldots m, \\
\sum_{k=1}^{K} \lambda_{k} y_{j k}^{s} \geq y_{j}^{t}, j=1,2, \ldots, n, \\
\lambda_{k} \geq 0, k=1,2, \ldots, K .
\end{gathered}
$$

In Eqs (6)-(7), variable $\phi \in(0,1]$ stands for efficiency score, where $\phi=1$ indicates full efficiency.

\subsection{Bias-corrected Malmquist index}

The changes in input distance function across different periods of analysis may be induced by different factors. Basically, these can be DMU-specific improvements in performance (catchup effect) and technology-wide shifts in frontier (technical change). Convolutions of these effects render changes in the total factor productivity (TFP). The input distance functions and DEA estimators thereof are employed to estimate TFP indices along with their components.

Assuming CRS, the change in TFP can be decomposed into efficiency change (catch-up) and technical change (frontier shift) components (Färe et al. 1994b). First, the change in TFP between periods $t$ and $t+1$ can be estimated via (Caves et al. 1982; Färe et al. 1994b): 


$$
M_{k}^{t, t+1}=\left(\frac{D_{k}^{t+1}\left(x_{k}^{t+1}, y_{k}^{t+1}\right)}{D_{k}^{t+1}\left(x_{k}^{t}, y_{k}^{t}\right)} \frac{D_{k}^{t}\left(x_{k}^{t+1}, y_{k}^{t+1}\right)}{D_{k}^{t}\left(x_{k}^{t}, y_{k}^{t}\right)}\right)^{0.5}
$$

where $k$ refers to the $k$-th DMU and $D_{k}^{p}\left(x_{k}^{q}, y_{k}^{q}\right), p \in\{t, t+1\}, q \in\{t, t+1\}$ refers to input distance function as defined by Eq. (4). Second, the change in TFP can be decomposed to isolate catch-up and frontier shift effects. The latter two effects are referred to as efficiency change (EC) and technical change (TC), respectively. Following Färe et al. (1994b, 1995a, 1995b), the Malmquist TFP index is decomposed as:

$$
M_{k}^{t, t+1}=\underbrace{\frac{D_{k}^{t+1}\left(x_{k}^{t+1}, y_{k}^{t+1}\right)}{D_{k}^{t}\left(x_{k}^{t}, y_{k}^{t}\right)}}_{E C_{k}^{t, t+1}} \underbrace{\left(\frac{D_{k}^{t}\left(x_{k}^{t}, y_{k}^{t}\right)}{D_{k}^{t+1}\left(x_{k}^{t}, y_{k}^{t}\right)} \frac{D_{k}^{t}\left(x_{k}^{t+1}, y_{k}^{t+1}\right)}{D_{k}^{t+1}\left(x_{k}^{t+1}, y_{k}^{t+1}\right)}\right)^{0.5}}_{T C_{k}^{t, t+1}},
$$

where the first component, EC, measures the change in the distance to the frontier and the second component, TC, measures the shift of the frontier along the ray through the origin and observation (a geometric average of shifts for periods $t$ and $t+1$ is considered).

Further decompositions of EC and TC are possible to account for various sources of change in TFP. Particularly, technical bias can be analyzed in the spirit of Färe et al. (1997). This framework was also applied by Weber and Domazlicky (1999), Managi and Karemera (2004), Barros and Weber (2009), Assaf and Barros (2011), Barros et al. (2012). In the latter framework, TC is further decomposed into the three components, viz. input biased technical change (IBTC), output biased technical change (OBTC), and magnitude of technical change (MTC):

$$
\begin{aligned}
\operatorname{OBTC}_{k}^{t, t+1} & =\left(\frac{D_{k}^{t}\left(x_{k}^{t+1}, y_{k}^{t+1}\right)}{D_{k}^{t+1}\left(x_{k}^{t+1}, y_{k}^{t+1}\right)} \frac{D_{k}^{t+1}\left(x_{k}^{t+1}, y_{k}^{t}\right)}{D_{k}^{t}\left(x_{k}^{t+1}, y_{k}^{t}\right)}\right)^{0.5} ; \\
\operatorname{IBTC}_{k}^{t, t+1} & =\left(\frac{D_{k}^{t+1}\left(x_{k}^{t}, y_{k}^{t}\right)}{D_{k}^{t}\left(x_{k}^{t}, y_{k}^{t}\right)} \frac{D_{k}^{t}\left(x_{k}^{t+1}, y_{k}^{t}\right)}{D_{k}^{t+1}\left(x_{k}^{t+1}, y_{k}^{t}\right)}\right)^{0.5} ; \\
\operatorname{MTC}_{k}^{t, t+1} & =\frac{D_{k}^{t}\left(x_{k}^{t}, y_{k}^{t}\right)}{D_{k}^{t+1}\left(x_{k}^{t}, y_{k}^{t}\right)}
\end{aligned}
$$

such that $T C_{k}^{t, t+1}=O B T C_{k}^{t, t+1} \cdot I B T C_{k}^{t, t+1} \cdot M T C_{k}^{t, t+1}$. Note that OBTC measures the change in curvature of the isoquant along the rays through the origin and output of both period $t$ and $t+1$ keeping the input quantity at the level of period $t+1$, whereas IBTC measures the change in curvature of the isoquant along the rays through the origin and input of both period $t$ and $t+1$ maintaining the output quantity at the level of period $t$. Finally, MTC measures frontier shift along the ray through the origin and initial observation, $\left(x_{k}^{t}, y_{k}^{t}\right)$. In case of a Hicks neutral technical change ${ }^{3}$, MTC would not depend on the base observation (i. e. direction of the ray from the origin).

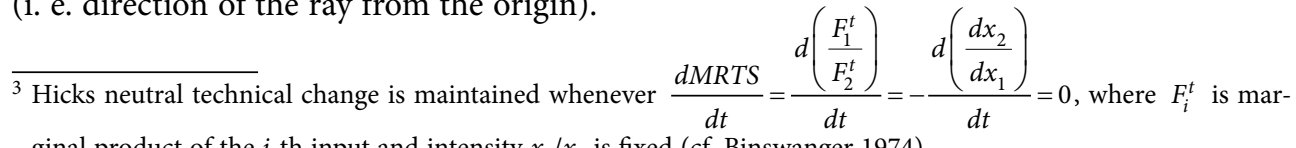
ginal product of the $i$-th input and intensity $x_{2} / x_{1}$ is fixed (cf. Binswanger 1974). 
In the present setting, based upon input distance functions, increase (resp. decrease) in TFP is indicated by values of $M_{k}^{t, t+1}$ lower (resp. greater) than unity. Similarly, EC, TC, IBTC, OBTC, and MTC contribute to increase (resp. decrease) in TFP if their values are lower (resp. higher) than unity.

Due to homogeneity of input distance function (Färe et al. 1994a), $D^{t}(\cdot)$, OBTC equals unity in case a single output is considered. In addition, IBTECH becomes independent of output (Färe et al. 2001). Table 1 below summarizes the possible outcomes of combinations of the factor intensity changes and IBTC.

Table 1. The types of input-biased technology change.

\begin{tabular}{|l|c|c|c|}
\hline & IBTC $>1$ & IBTC $<1$ & IBTC $=1$ \\
\hline$\left(x_{i} / x_{q}\right)_{t}<\left(x_{i} / x_{q}\right)_{t+1}$ & $x_{q}-$ using, $x_{i}-$ saving & $x_{i}-$ using, $x_{q}-$ saving & \multirow{2}{*}{ Neutral } \\
\cline { 1 - 3 }$\left(x_{i} / x_{q}\right)_{t}>\left(x_{i} / x_{q}\right)_{t+1}$ & $x_{i}-$ using, $x_{q}-$ saving & $x_{q}-$ using, $x_{i}-$ saving & \\
\hline
\end{tabular}

\section{Data used}

Provincial farm household input and output data for the selected crops are obtained from the Farm Production Costs and Returns Survey (FPCRS) published by the National Development and Reform Commission (NDRC), covering the period of 2004-2012. The data for 13,14 , and 18 provinces are available in regards to rice, wheat, and maize production, respectively. Furthermore, country averages are included for each time period.

We model the productive technology by considering one output variable (denoted as $Y$ ) and four inputs (denoted as $X \mathrm{~s})$. Note that all the variables are expressed per mu $(1 / 15$ hectare). The following variables are used to define the productive technology:

- Y: production quantity (in kilograms per mu).

- X1: labor input (in days per mu).

- X2: fertilizer input (pure-content quantity of chemical fertilizer applied annually in tons per mu).

- X3: machinery input includes expenditure on machinery and animals used annually (in RMB Yuan).

- X4: other inputs - the residual of deducting labor, fertilizer and machinery expenditures from the total production costs (in RMB Yuan). Pesticides, plastic film etc. are included in this variable.

The input variables measured in monetary terms (RMB Yuan) are all deflated by the real price indices with base year 1992. Machinery costs are deflated by the price index of agricultural machinery. Other inputs are deflated by the general price index of agricultural production materials.

As long as the variables used are normalized by a certain input (which is land in our case), the results are invariant with regards to assumption on returns to scale. Given we focus on an inter-provincial analysis based on aggregate data, the assumption of CRS is theoretically appropriate. Note that land input has been neglected in previous literature (e.g., Wang, Rungsuriyawiboon 2010). 


\section{Results}

In order to identify the main trends in grain production in China over 2004-2012, we focus on rice, wheat, and maize production there. Specifically, we analyze the patterns of technical efficiency and TFP change across different provinces by means of the bias-corrected Malmquist indices (cf. Section 3.3).

\subsection{Maize}

The following Table 2 presents period-wise changes in factor use intensity. The latter figures enable one to fathom the underlying changes in factor use in relative terms. Obviously, as the use of labor input per mu has generally decreased in all the provinces, labor intensity as measured against the use of the other inputs has decreased for all possible input combinations in $67-91 \%$ of observations. The substitution of machinery for labor is particularly evident (91\% of observations during 2004-2012). Note that certain provinces did not follow the general trend in regards to labor saving throughout most of the period of 2004-2014. Specifically, Guizhou and Sichuan did not increase fertilizer use relative to labor use in most of the periods, whereas Jilin, Sichuan, and Xinjiang feature increase in labor use relative to other inputs for at least a half of the periods within 2004-2012.

Table 2. Changes in factor use intensities for maize across Chinese provinces, 2004-2012

\begin{tabular}{|c|c|c|c|c|c|c|}
\hline Province & $X 2 / X 1$ & $X 3 / X 1$ & $X 4 / X 1$ & $X 3 / X 2$ & $X 4 / X 2$ & $X 4 / X 3$ \\
\hline Average & 8 & 8 & 6 & 8 & 4 & 1 \\
\hline Anhui & 6 & 6 & 6 & 5 & 3 & 1 \\
\hline Gansu & 5 & 8 & 6 & 8 & 5 & 1 \\
\hline Guizhou & 2 & 8 & 5 & 8 & 4 & 1 \\
\hline Hebei & 7 & 7 & 6 & 6 & 3 & 1 \\
\hline Heilongjiang & 8 & 8 & 5 & 7 & 2 & 2 \\
\hline Henan & 6 & 6 & 5 & 6 & 3 & 2 \\
\hline Hubei & 7 & 8 & 6 & 5 & 4 & 1 \\
\hline Yunnan & 6 & 8 & 6 & 6 & 4 & 2 \\
\hline Jiangsu & 5 & 7 & 6 & 6 & 5 & 2 \\
\hline Jilin & 6 & 7 & 3 & 5 & 2 & 3 \\
\hline Liaoning & 8 & 8 & 5 & 6 & 4 & 1 \\
\hline Inner Mongolia & 7 & 7 & 6 & 7 & 4 & 3 \\
\hline Ningxia & 5 & 6 & 6 & 6 & 5 & 3 \\
\hline Shaanxi & 5 & 8 & 6 & 7 & 4 & 0 \\
\hline Shandong & 7 & 8 & 6 & 7 & 5 & 1 \\
\hline Shanxi & 7 & 8 & 5 & 8 & 4 & 1 \\
\hline Sichuan & 3 & 7 & 4 & 7 & 4 & 2 \\
\hline Xinjiang & 7 & 6 & 4 & 5 & 3 & 2 \\
\hline Total & 115 & 139 & 102 & 123 & 72 & 30 \\
\hline Total, \% & 76 & 91 & 67 & 81 & 47 & 20 \\
\hline
\end{tabular}

Note: the numbers of periods of two consecutive years within 2004-2012 with increase in the ratios are given, 152 observations in total. 
Factor use intensity considering combinations of inputs with no labor involved show more homogeneity as opposed to the discussed cases. For only marginal deviations from the general trend are observed in regards to other input use relative to fertilizer use. In the latter case, Gansu, Jiangsu, Ningxia, and Shandong experienced increase in other input use intensity during five periods out of eight ones observed. Otherwise, the general trend was an increase in machinery use relative to fertilizer use, a decrease in other input use relative to fertilizer use, and a decrease in other input use relative to machinery use.

By the virtue of the bias-corrected Malmquist indices, we analyze the patterns of technical bias in maize production (Table 3). Considering the input combinations where labor is included, labor-saving TC is observed in $50-65 \%$ of the observations. The lowest rate is observed for other input substitution for labor. Gansu and Hebei show labor-using TC for most of the periods within 2004-2012 with respect to all the remaining inputs. At the other end of spectrum, substitution of machinery for labor prevails (65\% of observations). Besides

Table 3. The types of technical changes for maize across Chinese provinces, 2004-2012

\begin{tabular}{|c|c|c|c|c|c|c|}
\hline Province & $\begin{array}{l}X_{2}-\text { using / } \\
X_{1}-\text { saving }\end{array}$ & $\begin{array}{c}X_{3}-\text { using / } \\
X_{1}-\text { saving }\end{array}$ & $\begin{array}{c}X_{4}-\text { using / } \\
X_{1}-\text { saving }\end{array}$ & $\begin{array}{c}X_{3}-\text { using / } \\
X_{2}-\text { saving }\end{array}$ & $\begin{array}{l}X_{4}-\text { using / } \\
X_{2} \text { - saving }\end{array}$ & $\begin{array}{l}X_{4}-\text { using / } \\
X_{3}-\text { saving }\end{array}$ \\
\hline Average & 6 & 6 & 4 & 6 & 2 & 1 \\
\hline Anhui & 6 & 6 & 6 & 5 & 3 & 1 \\
\hline Gansu & 2 & 3 & 3 & 3 & 6 & 4 \\
\hline Guizhou & 5 & 5 & 4 & 5 & 3 & 2 \\
\hline Hebei & 4 & 2 & 3 & 3 & 6 & 6 \\
\hline Heilongjiang & 8 & 8 & 5 & 7 & 2 & 2 \\
\hline Henan & 5 & 3 & 6 & 3 & 4 & 5 \\
\hline Hubei & 6 & 7 & 5 & 6 & 3 & 0 \\
\hline Yunnan & 5 & 7 & 5 & 5 & 3 & 3 \\
\hline Jiangsu & 5 & 3 & 2 & 4 & 5 & 2 \\
\hline Jilin & 5 & 6 & 2 & 4 & 3 & 2 \\
\hline Liaoning & 6 & 6 & 5 & 4 & 4 & 3 \\
\hline Inner Mongolia & 5 & 5 & 6 & 5 & 4 & 5 \\
\hline Ningxia & 7 & 6 & 6 & 4 & 3 & 3 \\
\hline Shaanxi & 3 & 4 & 2 & 5 & 4 & 4 \\
\hline Shandong & 3 & 4 & 2 & 5 & 1 & 3 \\
\hline Shanxi & 5 & 6 & 3 & 6 & 2 & 1 \\
\hline Sichuan & 3 & 7 & 4 & 7 & 4 & 2 \\
\hline Xinjiang & 6 & 5 & 3 & 4 & 2 & 3 \\
\hline Total & 95 & 99 & 76 & 91 & 64 & 52 \\
\hline Total, \% & 63 & 65 & 50 & 60 & 42 & 34 \\
\hline
\end{tabular}

Note: the numbers of periods of two consecutive years within 2004-2012 with enumerated types of TC are given, 152 observations in total. 
the two aforementioned provinces, Henan and Jiangsu exhibit increasing labor intensity for most of the periods under analysis.

Fertilizer appeared as a substitute for labor and other inputs, yet it was not the case with respect to machinery. As regards fertilizer-saving and machinery-using TC, it is present for $60 \%$ of observations. However, Gansu and Hebei are the two provinces with the opposite trends considering fertilizer use. Other input-using and machinery saving is present only for $34 \%$ of observations. Therefore, machinery-using TC prevails in most of the provinces. Inner Mongolia, Henan, and Hebei can be mentioned as provinces, where other input-using and machinery-saving TC is observed for most of the periods.

\subsection{Rice}

As Table 4 suggests, labor intensity has decreased in all regions for most of time periods. The increase in machinery use intensity is also evident for all the regions and time periods. The only exemption is Zhejiang, where other inputs were used more intensively relative to machinery. Fertilizer use intensity has increased against all the inputs save machinery. Finally, other input intensity has increased against labor only, yet opposite trends are evident against the remaining inputs.

Table 4. Changes in factor use intensities for rice across Chinese provinces, 2004-2012

\begin{tabular}{|l|c|c|c|c|c|c|}
\hline \multicolumn{1}{|c|}{ Province } & $X 2 / X 1$ & $X 3 / X 1$ & $X 4 / X 1$ & $X 3 / X 2$ & $X 4 / X 2$ & $X 4 / X 3$ \\
\hline Average & 8 & 8 & 7 & 7 & 3 & 1 \\
\hline Anhui & 7 & 6 & 5 & 5 & 3 & 2 \\
\hline Hebei & 4 & 6 & 5 & 4 & 1 & 2 \\
\hline Heilongjiang & 7 & 7 & 5 & 6 & 4 & 2 \\
\hline Henan & 5 & 5 & 5 & 5 & 4 & 3 \\
\hline Hubei & 5 & 6 & 5 & 4 & 4 & 2 \\
\hline Yunnan & 8 & 7 & 5 & 5 & 3 & 1 \\
\hline Jiangsu & 6 & 6 & 4 & 7 & 3 & 3 \\
\hline Jilin & 7 & 8 & 4 & 7 & 2 & 0 \\
\hline Liaoning & 8 & 8 & 4 & 8 & 2 & 0 \\
\hline Inner Mongolia & 5 & 7 & 6 & 4 & 3 & 3 \\
\hline Ningxia & 7 & 8 & 5 & 7 & 3 & 4 \\
\hline Shandong & 6 & 6 & 7 & 6 & 3 & 1 \\
\hline Zhejiang & 6 & 8 & 7 & 6 & 5 & 5 \\
\hline Total & $\mathbf{8 9}$ & $\mathbf{9 6}$ & $\mathbf{7 4}$ & $\mathbf{8 1}$ & 43 & 29 \\
\hline Total, \% & $\mathbf{7 9}$ & $\mathbf{8 6}$ & $\mathbf{6 6}$ & $\mathbf{7 2}$ & 38 & $\mathbf{2 6}$ \\
\hline
\end{tabular}

Note: the numbers of periods of two consecutive years within 2004-2012 with increase in the ratios are given, 112 observations in total. 
Even though changes in factor use intensity were more or less uniform across provinces and time periods, the technical biases were not that uniform (Table 5). Indeed, the highest share of observations, viz., $86 \%$, are specific with increase in machinery-to-labor ratio, yet only $68 \%$ of observations experienced machinery-using and labor-saving TC (i.e., a nonneutral shift in the frontier). This implies that frontier provinces are less prone to changes in production technology possibly because of substantial results obtained via the "business as usual" practices. Jiangsu is the only province where labor-using TC prevailed with respect to fertilizer and machinery (however, this is not the case for other inputs). Similar trends are also observed for Ningxia, yet the machinery-using and labor-saving bias is more evident there. Anhui, Jilin, Liaoning, and Inner Mongolia are the four provinces with labor-using and other input-saving TC while others show the opposite trend. Machinery-using TC is observed for all input combinations, albeit Jiangsu and Ningxia machinery-saving and other input-using TC for most of the periods.

Table 5. The types of technical changes for rice across Chinese provinces, 2004-2012

\begin{tabular}{|c|c|c|c|c|c|c|}
\hline Province & $\begin{array}{c}X_{2}-\text { using / } \\
X_{1}-\text { saving }\end{array}$ & $\begin{array}{c}X_{3}-\text { using / } \\
X_{1}-\text { saving }\end{array}$ & $\begin{array}{c}X_{4}-\text { using / } \\
X_{1}-\text { saving }\end{array}$ & $\begin{array}{l}X_{3}-\text { using / } \\
X_{2}-\text { saving }\end{array}$ & $\begin{array}{c}X_{4}-\text { using / } \\
X_{2}-\text { saving }\end{array}$ & $\begin{array}{l}X_{4}-\text { using / } \\
X_{3}-\text { saving }\end{array}$ \\
\hline Average & 5 & 5 & 4 & 4 & 2 & 4 \\
\hline Anhui & 4 & 5 & 2 & 6 & 2 & 1 \\
\hline Hebei & 4 & 6 & 5 & 4 & 1 & 2 \\
\hline Heilongjiang & 7 & 7 & 5 & 6 & 4 & 2 \\
\hline Henan & 6 & 6 & 6 & 6 & 5 & 4 \\
\hline Hubei & 5 & 6 & 5 & 4 & 4 & 2 \\
\hline Yunnan & 5 & 4 & 4 & 4 & 2 & 4 \\
\hline Jiangsu & 3 & 3 & 5 & 6 & 6 & 6 \\
\hline Jilin & 6 & 7 & 3 & 6 & 1 & 1 \\
\hline Liaoning & 5 & 5 & 3 & 5 & 3 & 3 \\
\hline Inner Mongolia & 4 & 6 & 3 & 5 & 4 & 4 \\
\hline Ningxia & 3 & 4 & 5 & 3 & 5 & 6 \\
\hline Shandong & 6 & 6 & 7 & 6 & 5 & 3 \\
\hline Zhejiang & 6 & 6 & 5 & 4 & 5 & 5 \\
\hline Total & 69 & 76 & 62 & 69 & 49 & 47 \\
\hline Total, \% & 62 & 68 & 55 & 62 & 44 & 42 \\
\hline
\end{tabular}

Note: the numbers of periods of two consecutive years within 2004-2012 with enumerated types of TC are given, 112 observations in total.

\subsection{Wheat}

The decrease in labor use intensity is evident considering all the input combinations (Table 6). However, the lowest share of observations (if opposed to other input combinations including labor) showed increase in other input intensity against labor input. Therefore, the 
proportion of labor to other inputs varies across the provinces. The use of fertilizers has intensified against labor and other inputs, however, the opposite holds with respect to machinery. The intensity of machinery use has increased against all the inputs. Indeed, no provinces have deviated from this trend. Finally, the intensity of other inputs (pesticides etc.) has only increased with respect to labor input, whereas none of the provinces show suchlike trend for input combinations including fertilizer and machinery.

Table 6. Changes in factor use intensities for wheat across Chinese provinces, 2004-2012

\begin{tabular}{|l|c|c|c|c|c|c|}
\hline \multicolumn{1}{|c|}{ Province } & $X 2 / X 1$ & $X 3 / X 1$ & $X 4 / X 1$ & $X 3 / X 2$ & $X 4 / X 2$ & $X 4 / X 3$ \\
\hline Average & 7 & 8 & 6 & 6 & 3 & 1 \\
\hline Anhui & 6 & 6 & 6 & 5 & 3 & 2 \\
\hline Gansu & 5 & 8 & 6 & 6 & 2 & 1 \\
\hline Hebei & 7 & 7 & 7 & 6 & 3 & 3 \\
\hline Henan & 6 & 6 & 5 & 5 & 4 & 2 \\
\hline Hubei & 7 & 7 & 5 & 7 & 3 & 2 \\
\hline Yunnan & 7 & 7 & 6 & 6 & 3 & 1 \\
\hline Jiangsu & 6 & 8 & 5 & 5 & 4 & 2 \\
\hline Inner Mongolia & 7 & 7 & 5 & 5 & 3 & 3 \\
\hline Ningxia & 6 & 8 & 5 & 8 & 2 & 0 \\
\hline Shaanxi & 5 & 7 & 5 & 4 & 4 & 1 \\
\hline Shandong & 8 & 8 & 4 & 7 & 2 & 1 \\
\hline Shanxi & 6 & 8 & 4 & 5 & 4 & 2 \\
\hline Sichuan & 7 & 8 & 4 & 8 & 3 & 1 \\
\hline Xinjiang & 8 & 8 & 6 & 6 & 3 & 2 \\
\hline Total & $\mathbf{9 8}$ & $\mathbf{1 1 1}$ & $\mathbf{7 9}$ & $\mathbf{8 9}$ & 46 & $\mathbf{2 4}$ \\
\hline Total, \% & $\mathbf{8 2}$ & $\mathbf{9 3}$ & $\mathbf{6 6}$ & $\mathbf{7 4}$ & 38 & $\mathbf{2 0}$ \\
\hline
\end{tabular}

Note: the numbers of periods of two consecutive years within 2004-2012 with increase in the ratios are given, 120 observations in total.

The results in Table 7 imply that frontier provinces have followed the trends in factor intensity as described in Table 6 . Therefore, technical biases basically coincide with the trend in factor intensity. However, these changes have not been implemented to the same extent in all the frontier countries and some quantitative differences are thus present.

In general, the provinces experienced the labor-saving and machinery-using TC. Fertilizer-saving TC is only observed against machinery input. Other input using TC is only observed in relation to labor input, whereas the opposite holds in relation to remaining inputs. However, certain provinces do not follow these trends. Shaanxi features input-using TC against all the inputs. Ningxia shows labor-using TC against fertilizer and machinery inputs. Gansu, Shandong, and Shanxi exhibit labor-using TC against either fertilizer or machinery. Contrary to the general pattern, machinery-saving and fertilizer-using TC prevails in Jiangsu, 
Inner Mongolia, Ningxia, and Shaanxi. Jiangsu and Ningxia are specific with fertilizer-saving and other input-using TC. The latter two provinces should therefore seek for a decrease in application of chemical fertilizers and increase the use of machinery and other input (including organic fertilizer).

Table 7. The types of technical changes for wheat across Chinese provinces, 2004-2012

\begin{tabular}{|l|c|c|c|c|c|c|}
\hline \multicolumn{1}{|c|}{ Province } & $\begin{array}{c}X_{2}-\text { using / } \\
X_{1}-\text { saving }\end{array}$ & $\begin{array}{l}X_{3}-\text { using / } \\
X_{1}-\text { saving }\end{array}$ & $\begin{array}{c}X_{4} \text { - using / } \\
X_{1}-\text { saving }\end{array}$ & $\begin{array}{c}X_{3} \text { - using / } \\
X_{2} \text { - saving }\end{array}$ & $\begin{array}{c}X_{4}-\text { using / } \\
X_{2}-\text { saving }\end{array}$ & $\begin{array}{c}X_{4} \text { - using / } \\
X_{3} \text { - saving }\end{array}$ \\
\hline Average & 8 & 7 & 5 & 5 & 2 & 2 \\
\hline Anhui & 6 & 6 & 6 & 5 & 3 & 2 \\
\hline Gansu & 3 & 6 & 6 & 6 & 4 & 3 \\
\hline Hebei & 6 & 6 & 4 & 5 & 2 & 2 \\
\hline Henan & 6 & 6 & 5 & 5 & 4 & 2 \\
\hline Hubei & 7 & 7 & 5 & 7 & 3 & 2 \\
\hline Yunnan & 6 & 6 & 7 & 5 & 4 & 2 \\
\hline Jiangsu & 8 & 6 & 7 & 3 & 6 & 4 \\
\hline Inner Mongolia & 4 & 4 & 4 & 2 & 2 & 4 \\
\hline Ningxia & 3 & 3 & 4 & 3 & 7 & 5 \\
\hline Shaanxi & 2 & 2 & 2 & 3 & 3 & 4 \\
\hline Shandong & 6 & 6 & 2 & 5 & 0 & 1 \\
\hline Shanxi & 4 & 6 & 2 & 5 & 2 & 2 \\
\hline Sichuan & 6 & 7 & 5 & 7 & 4 & 2 \\
\hline Xinjiang & 8 & 8 & 6 & 6 & 3 & 2 \\
\hline Total & $\mathbf{8 3}$ & $\mathbf{8 6}$ & $\mathbf{7 0}$ & $\mathbf{7 2}$ & 49 & 39 \\
\hline Total, \% & $\mathbf{6 9}$ & $\mathbf{7 2}$ & $\mathbf{5 8}$ & $\mathbf{6 0}$ & 41 & 33 \\
\hline
\end{tabular}

Note: the numbers of periods of two consecutive years within 2004-2012 with enumerated types of TC are given, 120 observations in total.

\section{Conclusions}

Application of the bias-corrected Malmquist index shows a labor-saving technical change against all the remaining inputs for all the crops under analysis. The highest frequencies of fertilizer- and machinery-using, labor-saving technical changes were observed for wheat farming. Therefore, a reduction in labor intensity is the most promising for wheat if opposed to rice and maize. Furthermore, the substitution of other inputs (organic fertilizer, pesticides etc.) for labor is not that certain for maize, as only $50 \%$ of observations are related to this kind of technical change. Machinery substitution for labor is desirable as machinery-using technical changes prevail. However, as it was already said, more attention should be paid for increasing productivity of factor inputs. Otherwise, excessive investments might ensure factor substitution, yet not induce a substantial output growth. The technology is biased towards machinery input more frequently if compared to fertilizer input. Anyway, an appropriate application of fertilizers is likely to reduce labor and other input requirements as 
the frequency of fertilizer-using bias is close to that of machinery-using bias. The results also indicate that farmers tend to decrease labor intensity relative to machinery input even though no machinery-using technical change is present. The lowest discrepancy is that between fertilizer and other input use.

As regards the spatial variation of technical biases, the provinces are quite homogeneous in terms of grain crop production. However, such provinces as Hebei, Jiangsu, Shaanxi, and Gansu do not operate within the labor-saving region on the production frontiers of at least two grain crops. Most of these provinces are the deep-interior ones and feature vast amounts of flatlands. Therefore, labor-saving practices are not that important there in their current form. Finally, family-based management practices need to properly accommodate the observed trends in technical change in order to substantially boost the productivity. Therefore, systematization of the agricultural production is a topical issue in the country-wide perspective.

A certain caution has been around in regards to gains in TFP in Chinese agriculture. Indeed, Han (2014) already noticed that the recent modernization of Chinese agriculture did not yield the expected growth in output. This might be the result of labor-saving adjustments as machinery and fertilizer consumption does not generate substantial increase in crop yields. As Wang and Rungsuriyawiboon (2010) put it, lands distribution is extremely egalitarian in China. Therefore, small-scale farming is both willing to implement novel farming practices and, nevertheless, faces difficulties in exploiting the benefits of mechanization. In order to alleviate these issues, machinery sharing services are needed (e.g., machinery rings). Methodologically, the output change can also be attributed to technical bias (Karagiannis, Tzouveleka 2001). Given the differences geo-climatic conditions, infrastructure, and economic development existing across the Chinese regions, the meta-frontier approach (Fei, Lin 2016). These issues call for further research into dynamics of agricultural productivity and efficiency in China.

\section{Acknowledgements}

Support by National Natural Science Foundation of China (71803085, 71773051, 71673142 and 71303112), China Postdoctoral Science Foundation (2017M621766), Postdoctoral Research Funding Scheme of Jiangsu Province (2018K066B), Fundamental Research Funds for the Central Universities (SKCX2017002) is acknowledged. The authors are also grateful for the support from Priority Academic Program Development (PAPD) of Jiangsu Higher Education Institutions, Jiangsu Center for Food Security Studies and the Collaborative Innovation Center of Modern Grain Circulation\& Safety. The usual disclaimers apply.

\section{References}

Anderson, K.; Strutt, A. 2012. Agriculture and food security in Asia by 2030, Farm Policy Journal 9(4): 21-33. https://doi.org/10.2139/ssrn.2102459

Anderson, K.; Strutt, A. 2014. Food security policy options for China: lessons from other countries, Food Policy 49(1): 50-58. https://doi.org/10.1016/j.foodpol.2014.06.008

Assaf, A. G.; Barros, C. 2011. Performance analysis of the gulf hotel industry: a Malmquist index with bias correction, International Journal of Hospitality Management 30(4): 819-826.

https://doi.org/10.1016/j.ijhm.2011.01.002 
Baležentis, T. 2014. Total factor productivity in the Lithuanian family farms after accession to the EU: application of the bias-corrected Malmquist indices, Empirica 41(4): 731-746. https://doi.org/10.1007/s10663-013-9234-y

Barros, C. P.; Weber, W. L. 2009. Productivity growth and biased technological change in UK airports, Transportation Research Part E: Logistics and Transportation Review 45(4): 642-653. https://doi.org/10.1016/j.tre.2009.01.004

Barros, C. P.; Felício, J. A.; Fernandes, R. L. 2012. Productivity analysis of Brazilian seaports, Maritime Policy \& Management 39(5): 503-523. https://doi.org/10.1080/03088839.2012.705033

Binswanger, H. P. 1974. The measurement of technical change biases with many factors of production, American Economic Review 64: 964-976.

Brümmer, B.; Glauben, T.; Lu, W. 2006. Policy reform and productivity change in Chinese agriculture: a distance function approach, Journal of Development Economics 81(1): 61-79. https://doi.org/10.1016/j.jdeveco.2005.04.009

Cater, C. A.; Chen, J.; Chu, B. J. 2003. Agricultural productivity growth in China: farm level versus aggregate measurement, China Economic Review 14(1): 53-71. https://doi.org/10.1016/S1043-951X(02)00086-X

Caves, D. W.; Christensen, L. R.; Diewert, W. E. 1982. The economic theory of index numbers and the measurement of input, output, and productivity, Econometrica 50: 1393-1414. https://doi.org/10.2307/1913388

Charnes, A.; Cooper, W. W.; Rhodes, E. 1978. Measuring the efficiency of decision making units, European Journal of Operational Research 2(6): 429-444. https://doi.org/10.1016/0377-2217(78)90138-8

Chen, J. S. 2013. An analysis of China's rural economic situation in 2012 and outlook for 2013, Chinese Rural Economy 2: 4-11. (in Chinese)

Chen, P. C.; Yu, M.; Chang, C.; Hsu, S. 2008. Total factor productivity growth in China's agricultural sector, China Economic Review 19(4): 580-598. https://doi.org/10.1016/j.chieco.2008.07.001

Chen, Z.; Song, S. F. 2008. Efficiency and technology gap in China's agriculture: a regional meta-frontier analysis, China Economic Review 19(2): 287-296. https://doi.org/10.1016/j.chieco.2007.03.001

Chen, Z.; Huffman, W. E.; Rozelle, S. 2003. Technical efficiency of Chinese grain production: a stochastic production frontier approach. Paper prepared for presentation at the American Agricultural Economics Association Annual Meeting, Montreal, Canada, July, 27-30.

Chen, Z.; Huffman, W. E.; Rozelle, S. 2009. Farm technology and technical efficiency: evidence from four regions in China, China Economic Review 20(2): 153-161.

https://doi.org/10.1016/j.chieco.2009.03.002

Fan, S. G. 1991. Effects of technological change and institutional reform on production growth in Chinese agriculture, American Journal of Agricultural Economics 73(2): 266-275. https://doi.org/10.2307/1242711

Fan, S. G. 1997. Production and productivity growth in Chinese agriculture: new measurement and evidence, Food Policy 22(3): 213-228. https://doi.org/10.1016/S0306-9192(97)00010-9

Fan, S. G.; Zhang, X. B. 2002. Production and productivity growth in Chinese agriculture: new national and regional measures, Economic Development and Cultural Change 50(4): 819-838. https://doi.org/10.1086/343136

FAO-OECD. 2013. Agricultural Outlook 2013-2022. OECD Publishing.

Färe, R.; Grifell-Tatjé, E.; Grosskopf, S.; Knox Lovell, C. A. 1997. Biased technical change and the Malmquist productivity index, The Scandinavian Journal of Economics 99(1): 119-127. https://doi.org/10.1111/1467-9442.00051

Färe, R.; Grosskopf, S.; Lee, W. F. 1995a. Productivity in Taiwanese manufacturing industries, Applied Economics 27(3): 259-265. https://doi.org/10.1080/00036849500000109

Färe, R.; Grosskopf, S.; Lee, W. F. 2001. Productivity and technical change: the case of Taiwan, Applied Economics 33(15): 1911-1925. https://doi.org/10.1080/00036840010018711 
Färe, R.; Grosskopf, S.; Lovell, C. K. 1994a. Production frontiers. Cambridge University Press.

Färe, R.; Grosskopf, S.; Roos, P. 1995b. Productivity and quality changes in Swedish pharmacies, International Journal of Production Economics 39(1): 137-144. https://doi.org/10.1016/0925-5273(94)00063-G

Färe, R.; Grosskopf, S.; Norris, M.; Zhang, Z. 1994b. Productivity growth, technical progress, and efficiency change in industrialized countries, American Economic Review 84: 66-83.

Färe, R.; Grosskopf, S.; Margaritis, D. 2008. Efficiency and productivity: Malmquist and more, Chapter 5, in H. O. Fried, C. A. K. Lovell, S. Schmidt (Eds.). The measurement of productive efficiency and productivity growth. Oxford: Oxford University Press. https://doi.org/10.1093/acprof:oso/9780195183528.003.0005

Fei, R. L.; Lin, B. Q. 2016. Energy efficiency and production technology heterogeneity in China's agricultural sector: a meta-frontier approach, Technological Forecasting and Social Change 109: 25-34. https://doi.org/10.1016/j.techfore.2016.05.012

Han, G. Q. 2014. Mechanization and dynamic management in modern Chinese agriculture, Acta Agriculturae Scandinavica, Section B - Soil \& Plant Science 63: 100-104.

Hayami, Y.; Ruttan, V. M. 1970. Factor prices and technical change in agricultural development: the United States and Japan, 1880-1960, Journal of Political Economy 78(5): 1115-1141. https://doi.org/10.1086/259694

Hayami, Y.; Ruttan, V. M. 1971. Agricultural development: an international perspective. Baltimore: Johns Hopkins University Press.

Hu, B. D.; McAleer, M. 2005. Estimation of Chinese agricultural production efficiencies with panel data, Mathematics and Computers in Simulation 68(5): 475-484. https://doi.org/10.1016/j.matcom.2005.02.002

Huang, J. K.; Rozelle, S. 1996. Technological change: rediscovering the engine of productivity growth in China's rural economy, Journal of Development Economics 49(2): 337-369. https://doi.org/10.1016/0304-3878(95)00065-8

Ito, J. 2010. Inter-regional difference of agricultural productivity in China: distinction between biochemical and machinery technology, China Economic Review 21(3): 394-410. https://doi.org/10.1016/j.chieco.2010.03.002

Jin, S. Q.; Huang, J. K.; Hu, R. F.; Rozelle, S. 2002. The creation and spread of technology and total factor productivity in China's agriculture, American Journal of Agricultural Economics 84(4): 916-930. https://doi.org/10.1111/1467-8276.00043

Jin, S. Q.; Ma, H. Y.; Huang, J. K.; Hu, R. F.; Rozelle, S. 2010. Productivity, efficiency and technical change: measuring the performance of China's transforming agriculture, Journal of Productivity Analysis 33(3): 291-207. https://doi.org/10.1007/s11123-009-0145-7

Karagiannis, G.; Tzouvelekas, V. 2001. Self-dual stochastic production frontiers, and decomposition of output growth: the case of the olive growing farms in Greece, Agricultural and Resource Economics Review 30(2): 168-178. https://doi.org/10.1017/S1068280500001118

Lambert, D. K.; Parker, E. 1998. Productivity in Chinese provincial agriculture, Journal of Agricultural Economics 49(3): 378-392. https://doi.org/10.1111/j.1477-9552.1998.tb01279.x

Li, G. C.; You, L. Z.; Feng, Z. C. 2011. The sources of total factor productivity growth in Chinese agriculture: technological progress or efficiency gain?, Journal of Chinese Economic and Business Studies 9(2): 181-203. https://doi.org/10.1080/14765284.2011.568686

Li, Z.; Zhang, H. P. 2013. Productivity growth in China's agriculture during 1985-2010, Journal of Integrative Agriculture 12(10): 1896-1904. https://doi.org/10.1016/S2095-3119(13)60598-5

Liu, W. J. 2011. Regional technical efficiency and technology gaps in rural China: evidence from CHIP surveys, China Economic Journal 4(2-3): 125-144. https://doi.org/10.1080/17538963.2011.666058 
Luh, Y. H.; Chang, C. C.; Huang, F. M. 2008. Efficiency change and productivity growth in agriculture: a comparative analysis for selected East Asian economies, Journal of Asian Economics 19(4): 312-324. https://doi.org/10.1016/j.asieco.2008.05.003

Ma, S. Z.; Feng, H. 2013. Will the decline of efficiency in China's agriculture come to an end? An analysis based on opening and convergence, China Economic Review 27: 179-190. https://doi.org/10.1016/j.chieco.2013.04.003

Managi, S.; Karemera, D. 2004. Input and output biased technological change in US agriculture, Applied Economics Letters 11(5): 283-286. https://doi.org/10.1080/1350485042000221526

Mao, W. N.; Koo, W. 1997. Productivity growth, technological progress, and efficiency change in Chinese agriculture after rural economic reforms: a DEA approach, China Economic Review 8(2): 157-274. https://doi.org/10.1016/S1043-951X(97)90004-3

Monchuk, D. C.; Chen, Z.; Bonaparte, Y. 2010. Explaining production inefficiency in China's agriculture using data envelopment analysis and semi-parametric bootstrapping, China Economic Review 21(2): 346-354. https://doi.org/10.1016/j.chieco.2010.02.004

Nin, A.; Arndt, C.; Preckel, P. V. 2003. Is agricultural productivity in developing countries really shrinking? New evidence using a modified nonparametric approach, Journal of Development Economics 71(2): 395-415. https://doi.org/10.1016/S0304-3878(03)00034-8

Nin-Pratt, A.; Yu, B. X.; Fan, S. G. 2010. Comparisons of agricultural productivity growth in China and India, Journal of Productivity Analysis 33(3): 209-223. https://doi.org/10.1007/s11123-009-0156-4

O'Donnell, C. J. 2012. An aggregate quantity framework for measuring and decomposing productivity change, Journal of Productivity Analysis 38: 255-272. https://doi.org/10.1007/s11123-012-0275-1

Shephard, R. W. 1970. Theory of cost and production functions. Princeton, New Jersey: Princeton University Press.

Tian, W. M.; Wan, G. H. 2000. Technical efficiency and its determinants in China's grain production, Journal of Productivity Analysis 13(2): 159-174. https://doi.org/10.1023/A:1007805015716

Wang, J. M.; Xiao, H. B. 2013. The nature and prospects of the continuously growth of China's grain output in 8 years, Issues in Agricultural Economy 2: 22-30. (in Chinese)

Wang, J. M.; Zhang, H. J.; Liu, C. F.; Xiao, H. B.; Liang, X. 2013. Research on the construction of agricultural science and technology extension system in China, Grass-roots Agricultural Technology Extension 1(8): 1-16. (in Chinese).

Wang, X. B.; Rungsuriyawiboon, S. 2010. Agricultural efficiency, technical change and productivity in China, Post-Communist Economies 22(2): 207-227. https://doi.org/10.1080/14631371003740704

Weber, W. L.; Domazlicky, B. R. 1999. Total factor productivity growth in manufacturing: a regional approach using linear programming, Regional Science and Urban Economics 29(1): 105-122. https://doi.org/10.1016/S0166-0462(98)00013-1

Wu, S. X.; Walker, D.; Devadoss, S.; Lu, Y. 2001. Productivity growth and its components in Chinese agriculture after reform, Review of Development Economics 5(3): 375-391. https://doi.org/10.1111/1467-9361.00130

Xin, X. F.; Qin, F. 2011. Decomposition of agricultural labor productivity growth and its regional disparity in China, China Agricultural Economic Review 3(1): 92-100.

Yao, S. J.; Liu, Z. N. 1998. Determinants of grain production and technical efficiency in China, Journal of Agricultural Economics 49(2): 171-184. https://doi.org/10.1111/j.1477-9552.1998.tb01262.x

Yao, S. J.; Liu, Z. N.; Zhang, Z. Y. 2001. Spatial differences of grain production efficiency in China, 1987-1992, Economics of Planning 34(1-2): 139-157. https://doi.org/10.1023/A:1017599518985

Zhang, Y. J.; Brümmer, B. 2011. Productivity change and the effects of policy reform in China's agriculture since 1979, Asian-Pacific Economic Literature 25(2): 131-150. https://doi.org/10.1111/j.1467-8411.2011.01307.x

Zhou, L.; Zhang, H. P. 2013. Productivity growth in China's agriculture during 1985-2010, Journal of Integrative Agriculture 12(10): 1896-1904. https://doi.org/10.1016/S2095-3119(13)60598-5 